\title{
Nedocromil Sodium
}

National Cancer Institute

\section{Source}

National Cancer Institute. Nedocromil Sodium. NCI Thesaurus. Code C47635.

The sodium salt form of nedocromil, a pyranoquinolone derivative with anti-

inflammatory properties. Nedocromil sodium inhibits the activation and release of inflammatory mediators (leukotrienes, histamine and prostaglandins) from a variety of cells involved in hypersensitivity reactions, including mast cells, eosinophils, neutrophils, macrophages, monocytes and platelets. As a result, nedocromil sodium inhibits both immediate and late bronchoconstriction, decreases bronchial hyperresponsiveness and inhibits recruitment of other inflammatory cells into the airway epithelium. 